\title{
Chylous ascites as a consequence of idiopathic pancreatitis
}

\author{
Chwanrow Karim Baban, ${ }^{1}$ Michael Murphy, ${ }^{2}$ Cristóir O'Sulleabháin, ${ }^{3}$ \\ Deirdre O'Hanlon ${ }^{1}$
}

${ }^{1}$ Department of Surgery, South Infirmary Victoria University Hospital, Cork, Ireland ${ }^{2}$ Department of Radiology, South Infirmary Victoria University Hospital, Cork, Ireland

${ }^{3}$ Department of Surgery, Mercy University Hospital, Cork, Ireland

\section{Correspondence to} D O'Hanlon, Department of Surgery, South Infirmary Victoria University Hospital, Old Blackrock Road, Cork, Ireland;

deirdreohanlon@hotmail.com

All authors contributed equally to this paper.
CrossMark

\begin{tabular}{|l|}
\hline To cite: Baban CK, \\
Murphy M, O'Sulleabháin C, \\
et al. BMJ Case Rep \\
Published online: [please \\
include Day Month Year] \\
doi:10.1136/bcr-2013- \\
200132 \\
\hline
\end{tabular}

\section{SUMMARY}

Chylous ascites (chyloperitoneum) is a rare clinical condition, characterized by an accumulation of lymph fluid in the peritoneal cavity. Most commonly it is associated with abdominal malignancy (usually lymphoma). We present an unusual case of a woman who developed a persistent pseudocyst and recurrent chylous ascites following acute necrotizing pancreatitis.

\section{BACKGROUND}

We report a case of pancreatitis that was complicated with chylous ascites which was resistant to conservative measures, including dietary modification. More aggressive therapy in the form of fasting the patient with total parenteral nutrition (TPN) for 6 weeks allowed resolution. ${ }^{1}$

\section{CASE PRESENTATION}

A previously well 53-year-old woman presented with a 10 day history of worsening abdominal pain. Examination revealed diffuse abdominal tenderness with normal vital signs. Her Ranson's criteria were two on admission (white blood cell count $26 \times 10^{9}$ leukocytes/L; lactate dehydrogenase $749 \mathrm{iu} / \mathrm{L}$ ). Serum amylase was approximately $2509 \mathrm{IU} / \mathrm{L}$ and C reactive protein was $488.3 \mathrm{mg} / \mathrm{L}$, which was equivalent to two on the Glasgow criteria and was diagnosed as acute mild pancreatitis. At $48 \mathrm{~h}$, Ranson's criteria were four (base excess $-4.2 \mathrm{mEq} / \mathrm{L}$; $>6 \mathrm{~L}$ fluid sequestered; urea rise $18.2 \mathrm{mmol} / \mathrm{L}$; calcium $1.52 \mathrm{mmol} / \mathrm{L}$ ) which corresponds to Glasgow criteria being four, and she was in acute severe pancreatitis and developed acute renal failure and respiratory distress.

\section{INVESTIGATIONS}

CT scan demonstrated a diffusely edematous pancreas, with an inflammatory phlegmon (figure 1) on ultrasound, and magnetic resonance cholangiopancreatography showed no evidence of gallstones, common bile duct, or pancreatic duct abnormality. Subsequent imaging demonstrated an evolving acute fluid collection, and only the uncinate process and a portion of the tail remained perfused, which corresponds to a Baltazar score of $\mathrm{C}$ at the early stage and $\mathrm{D}$ at the later stage (figure $2 \mathrm{~A}, \mathrm{~B}$ ).

She was managed in the intensive care unit with full support from medical, surgical, dietician, physiotherapist, and other supportive therapies. She improved and was discharged home on day 41 . There was no history of alcohol excess, and no definite cause for the pancreatitis was found. She did

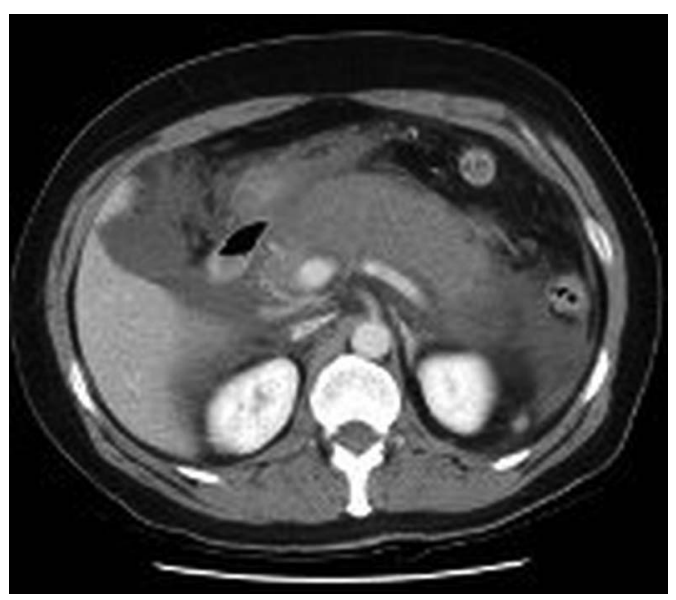

Figure 1 Axial CT image demonstrating diffusely an edematous poorly perfused pancreas with associated ascites.

have a past medical history of hyperlipidemia and was receiving atorvastatin, but her lipid profile and parathyroid hormone were normal. ${ }^{2}$

A follow-up ultrasound demonstrated an $11 \times 7.5 \mathrm{~cm}$ pseudocyst. While awaiting endoscopic ultrasound she presented (at 18 weeks) with marked ascites. Drainage of ascites was undertaken which resolved her acute symptoms. The paracentesis demonstrated chylous ascites. The color of the ascites was milky, with an elevated triglyceride level of $3538 \mathrm{mg} / \mathrm{dL}$, and normal glucose and amylase levels. Total protein was $3.9 \mathrm{~g} / \mathrm{dL}$ and a high leukocyte count, and all cultures were negative. The patient's biochemical profile was as follows: sodium $135 \mathrm{mmol} / \mathrm{L}$, potassium $4 \mathrm{mmol} / \mathrm{L}$, urea $4 \mathrm{mmol} / \mathrm{L}$, creatinine $63 \mu \mathrm{mol} / \mathrm{L}$, albumin $27 \mathrm{~g} / \mathrm{L}$, and amylase $84 \mathrm{U} / \mathrm{L}$. Culture was negative, including for mycobacterium. No malignant cells were seen. Endoscopic ultrasound demonstrated a grossly abnormal pancreas with extensive parenchymal calcification, the visualized pancreatic duct appeared normal, and no stone in the pancreatic duct and thoracic duct appeared patent. Specialist opinion recommended total paracentesis by percutaneous aspiration of cyst. Chylous fluid (5 L) was drained under CT guidance (figure 3 ). This was carried out under CT guidance rather than gastrocystostomy as per the patient's preference, followed by dietary modification.

\section{TREATMENT}

Initially the patient was commenced on a medium chain triglyceride (MCT) rich diet, but her 

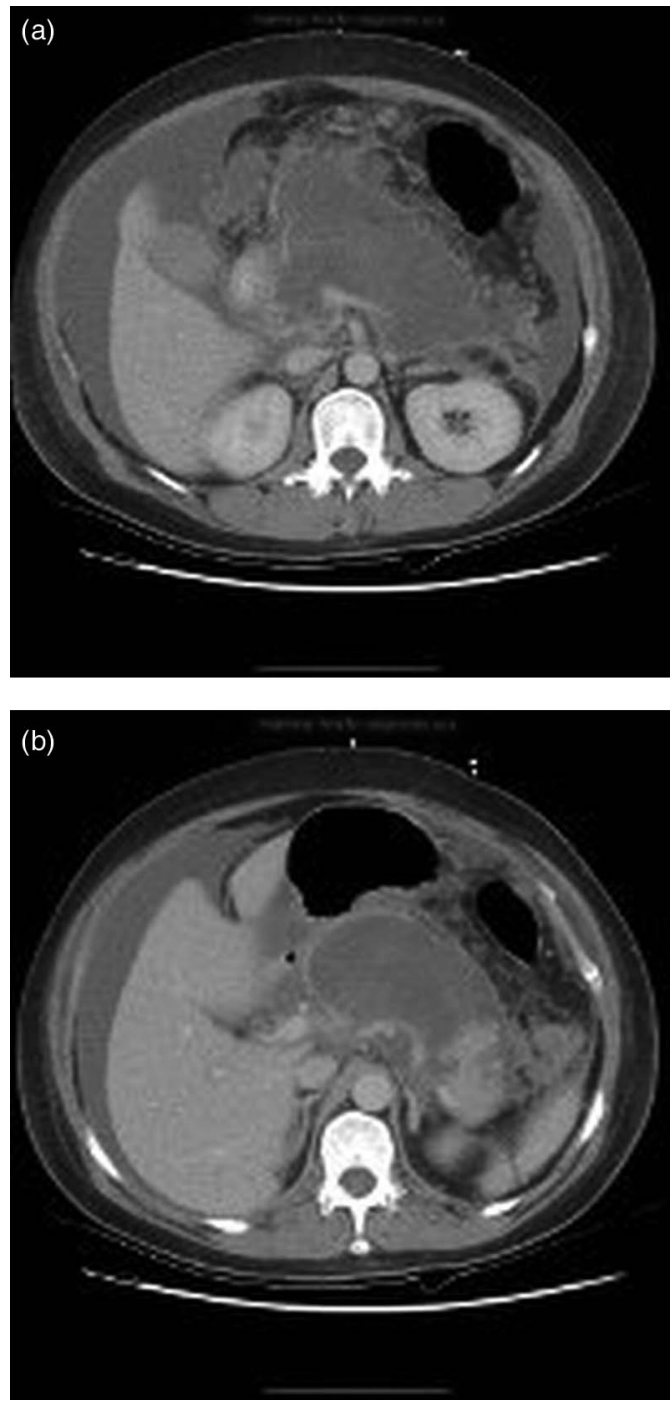

Figure 2 (A) Axial CT demonstrating necrosis of the pancreas with associated collection of only a portion of the uncinate. (B) The distal tail remained perfused.

adherence to this was, by her own account, less than optimal. Over the following 7 months, the patient presented on nine occasions to our service with gross ascites (and on one occasion

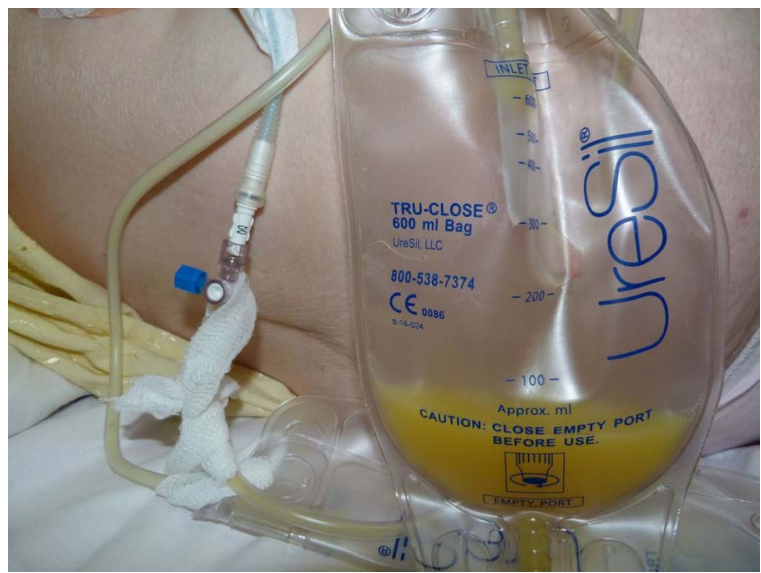

Figure 3 Chylous ascites draining. to a hospital in France, where she was holidaying). The interval between presentations varied between 14 and 36 days (average $\sim 21$ days), and on each occasion between 5 and $7 \mathrm{~L}$ of chylous fluid were aspirated; once the ascites were aspirated, the patient was anxious for discharge.

\section{OUTCOME AND FOLLOW-UP}

She was subsequently commenced on TPN with MCTs, and a somatostatin analog (lanreotide) for 6 weeks. This reduced her chylous ascites to such an extent that she has not required any further paracentesis.

\section{DISCUSSION}

The word ascites is derived from the Greek word askos meaning bag or bladder. ${ }^{3}$ In developed countries, the commonest causes of chylous ascites are intra-abdominal malignancy (lymphomas) and cirrhosis. In developing countries, the commonest etiology is infection with tuberculosis and filariasis. Other etiologies are congenital, traumatic (including postoperative), and inflammatory causes, such as acute or chronic pancreatitis, ${ }^{45}$ or following radiotherapy. More rare causes which have been described include constrictive pericarditis (increases lymph production by increasing hepatic venous flow), retroperitoneal fibrosis, ${ }^{6}$ sarcoidosis, $^{7}$ and Whipple's disease.

In children, causes include congenital lymphatic abnormalities such as primary lymphatic hypoplasia, but obstructive or idiopathic lesions caused by malrotation, intussusception, lymphangioma, and incarcerated hernia can occur. Battered child syndrome must be excluded in children with chylous ascites as it is the underlying cause in up to $10 \%$ of pediatric cases. ${ }^{9}$

Three main pathophysiological mechanisms have been postulated for chylous ascites ${ }^{10}$ :

1. obstruction of the flow of lymph fluid caused by external pressure (eg, a mass) leading to leakage from dilated subserosal lymphatic channels into the peritoneal cavity;

2. lymph exuding through the walls of dilated retroperitoneal vessels without valves, which leak fluid through a fistula into the peritoneal cavity, as in congenital lymphangectasia; and

3. traumatic obstruction of the thoracic duct causing direct leakage of lymph through a lymphoperitoneal fistula.

The treatment options are many and varied, and although the underlying cause should be addressed whenever possible, a conservative approach may be successful. If this is unsuccessful, patients are often prescribed a diet with high levels of proteins and low levels of lipids, and for these lipids to be exclusively in the form of MCTs to reduce peritoneal lymph flow.

The logic of limiting fat intake to MCTs is that by abstaining from long chain triglycerides, the production of monoglycerides and free fatty acids (formed when these are hydrolyzed) are avoided, which are carried as chylomicrons to the intestinal lymph ducts. MCTs, on the other hand, are absorbed directly by the intestinal mucosal cell and transported to the liver as free fatty acids and glycerol via the portal vein. This is to enable any chylous fistula to heal naturally. This has been shown to give at best a partial effect; two studies looking at outcomes in a pediatric population showed a limited response. ${ }^{11} 12$

There is some debate as to whether this is best delivered by oral dietary measures or by enteric rest with TPN. TPN has the advantage of counteracting the potential for dietary insufficiency (including any increased loss of fat and protein following repeated paracenteses), with the added advantage of associated fasting, which further reduces intestinal lymph flow.

Somatostatin is an inhibitory hormone which inhibits the release of growth hormone, thyroid stimulating hormone, and 
gastrointestinal hormones (such as cholecystokinin, vasoactive intestinal peptide, and gastrin), and also lowers the rate of gastric emptying as well as reducing smooth muscle contraction and blood flow within the gut. Octreotide and lanreotide are synthetic analogs of somatostatin, which decrease intestinal blood flow, thereby reducing lymph secretion through somatostatin receptors in the intestinal wall. ${ }^{13}$

Octreotide has previously been used to treat postpancreatitic chylous ascites in a report from Nova Scotia ${ }^{14}$ but there have been no reports of lanreotide being used successfully. However, the combination of both a somatostatin analog and TPN has been shown in a Chinese study to be successful, although the numbers involved were low.

\section{Learning points}

We report a rare complication of a condition routinely seen in general surgical practice, which failed to respond to conservative measures, including dietary modification, but resolved following more aggressive therapy which necessitated fasting the patient for 6 weeks plus total parenteral nutrition and somatostatin analog.

Competing interests None.
Patient consent Obtained.

Provenance and peer review Not commissioned; externally peer reviewed.

\section{REFERENCES}

1 Khan FY, Matar I. Chylous ascites secondary to hyperlipidemic pancreatitis with normal serum amylase and lipase. World I Gastroenterol 2007;13:480.

2 Pepper OHP. Medical etymology. Philadelphia: Saunders, 1949.

3 Zhang ZY, Howard JM. Chylous ascites. A late complication of massive peripancreatic necrosis. Int I Pancreatol 1997;21:259-61.

4 Khan FY, Matar I. Chylous ascites secondary to hyperlipidemic pancreatitis with normal serum amylase and lipase. World I Gastroenterol 2007;13:480-2.

5 Gilkeson GS, Allen NB. Retroperitoneal fibrosis. A true connective tissue disease. Rheum Dis Clin North Am 1996;22:23-38.

6 Cappell MS, Friedman D, Mikhail N. Chyloperitoneum associated with chronic severe sarcoidosis. Am J Gastroenterol 1993;88:99-101.

7 Isenberg Jl, Gilbert SB, Pitcher JL. Ascites with peritoneal involvement in Whipple's disease. Report of a case. Gastroenterology 1971;60:305-10.

8 Beshay VE, Beshay JE, Rosenberg AJ. Chylous ascites: a case of child abuse and an overview of a rare condition. J Pediatr Gastroenterol Nutr 2001;32:487-9.

9 Browse NL, Wilson NM, Russo F, et al. Aetiogy and treatment of chylous ascites. Br J Surg 1992;79:1145-50.

10 Unger SW, Chandler JG. Chylous ascites in infants and children. Surgery 1983;93:455-61.

11 Man DW, Spitz L. The management of chylous ascites in children. J Pediatr Surg 1985:20:72-5.

12 Bhatia C, Pratap U, Slavik Z. Octreotide therapy: a new horizon in treatment of iatrogenic chyloperitoneum. Arch Dis Child 2001;85:234-5.

13 Al-Ghamdi MY, Bedi A, Reddy SB, et al. Chylous ascites secondary to pancreatitis: management of an uncommon entity using parenteral nutrition and octreotide. Dig Dis Sci 2007.

14 Huang Q, Jiang ZW, Jiang J, et al. Chylous ascites: treated with total parenteral nutrition and somatostatin. World I Gastroenterol 2004:10:2588-91.

Copyright 2014 BMJ Publishing Group. All rights reserved. For permission to reuse any of this content visit

http://group.bmj.com/group/rights-licensing/permissions.

BMJ Case Report Fellows may re-use this article for personal use and teaching without any further permission.

Become a Fellow of BMJ Case Reports today and you can:

- Submit as many cases as you like

- Enjoy fast sympathetic peer review and rapid publication of accepted articles

- Access all the published articles

- Re-use any of the published material for personal use and teaching without further permission

For information on Institutional Fellowships contact consortiasales@bmjgroup.com

Visit casereports.bmj.com for more articles like this and to become a Fellow 